\title{
Poéticas da migrância e ditadura: exílio e diáspora nas obras de Julián Fuks e Francisco Maciel
}

\author{
Poetics of migration and dictatorship: exile and diaspora in \\ the works of Julián Fuks and Francisco Maciel
}

\author{
Poética de la migrancia y la dictadura: el exilio y la diáspora en \\ las obras de Julián Fuks y Francisco Maciel
}

Pádua Fernandes

\begin{abstract}
Resumo
$\mathrm{O}$ artigo trata da questão dos exílios e das migrações, em relação à ditadura militar, em dois autores da literatura brasileira contemporânea: Julián Fuks e Francisco Maciel. O romance A resistência (Fuks, 2015) é analisado segundo os conceitos de pós-memória (Hirsch, 2008) e privatização do trauma (Seligmann-Silva, 2014). Este romance, em sua tentativa de construir a memória da família relacionada ao exílio de pais argentinos e à adoção de um filho, retrata, nas dificuldades formais de escrever o livro, os problemas políticos do processo de justiça de transição no Brasil, em comparação com a Argentina. Na obra de Francisco Maciel, a discriminação racial contra a população negra é um tema central. A repressão política considerava que o movimento negro representava ameaça contra a segurança nacional. $\mathrm{O}$ artigo analisa a questão das migrações dos negros na obra de Maciel em termos de diáspora (Hall, 2003), e explica como ela não se torna apenas tema, mas também forma literária, no romance Não adianta morrer (Maciel, 2018).
\end{abstract}

Palavras-chave: ditadura militar, justiça de transição, literatura brasileira contemporânea, Julián Fuks, Francisco Maciel.

\begin{abstract}
This article deals with the question of exiles and migrations, in relation to the military dictatorship, in two authors of contemporary Brazilian literature: Julián Fuks and Francisco Maciel. It analyses the novel A resistência (Fuks, 2015) according to the concepts of post-memory (Hirsch, 2008) and privatization of trauma (Seligmann-Silva, 2014). Fuks's novel, in its attempt to construct a family's memory of exile and adoption, portrays, through the formal difficulties of writing the book, the political problems of the transitional justice process in Brazil in comparison to Argentina. In the work of Francisco Maciel, racial discrimination against the black population is a central theme. The black movement posed a threat to national security, according to the forces of political oppression. This article analyzes black migrations in Maciel's work through the lens of diaspora (Hall, 2003), and explains how diaspora becomes not only a theme, but also a literary form, in the novel Não adianta morrer (Maciel, 2018).
\end{abstract}

Keywords: military dictatorship, transitional justice, contemporary Brazilian literature, Julián Fuks, Francisco Maciel.

\begin{abstract}
Resumen
El artículo aborda el tema del exilio y de las migraciones, en relación con la dictadura militar, en dos autores de literatura brasileña contemporánea: Julián Fuks y Francisco Maciel. Los conceptos de postmemoria (Hirsch, 2008) y privatización del trauma (Seligmann-Silva, 2014) son utilizados en el análisis de la novela A resistência (Fuks, 2015). En su intento de construir la memoria familiar (relacionada con el exilio de los padres argentinos y con la adopción de un niño), esta novela retrata, ante las dificultades formales de escribir el libro, los problemas políticos del proceso de justicia transicional en Brasil, en comparación con Argentina. En cambio, la discriminación racial contra la población negra es el tema central en el libro de Francisco Maciel. La represión política consideró que el movimiento negro representaba una amenaza para la seguridad nacional. El artículo examina el tema de las migraciones negras en el trabajo de Maciel en términos de la diáspora (Hall, 2003), y explica cómo se convierte no sólo en un tema sino también en una forma literaria en la novela Não adianta morrer (Maciel, 2018).
\end{abstract}

Palabras-clave: dictadura militar, justicia transicional, literatura brasileña contemporânea, Julián Fuks, Francisco Maciel.

\footnotetext{
* Pós-doutorando em Teoria da Literatura na Universidade Estadual de Campinas (Unicamp), Campinas, SP, Brasil. orcid.org/0000-0003-3630-5175 E-mail: paduafernandes@hotmail.com
} 


\section{Literatura brasileira e ditadura, da redemocratização ao exílio}

A ditadura militar gerou, já a partir dos anos 1970 e 1980, uma literatura sobre o exílio, e alguns de seus autores viveram essa experiência; o período seguinte à lei de anistia, de 1979, foi marcado pelos "relatos autobiográficos de ex-presos políticos exilados [...] ou recém-saídos da prisão ou da clandestinidade (Figueiredo, 2017, p. 48). A ditadura militar instituiu o banimento de cidadãos brasileiros por simples ato do Poder Executivo, sem possibilidade de revisão judicial ${ }^{1} \mathrm{e}$, durante o governo Médici, criou o lema "Brasil: ame-o ou deixe-o", ${ }^{2}$ voltado contra os banidos e os exilados. Da mesma forma, muitos estrangeiros foram expulsos em razão de sua atividade política ou militância social.

Não se sabe, porém, quantos foram os atingidos por essas medidas da repressão política. As estatísticas oficiais da época subestimavam o número, como apontou a Comissão Nacional da Verdade: "Documento do Serviço Nacional de Informação (SNI) registra 2.692 exilados em 1979 e, entre eles, 278 militares. Esses dados não refletem a realidade. Centenas de brasileiros foram para o exílio no pós-64 e outros tantos após 1968, em razão do AI-5" (Brasil, 2014b, p. 39).

Apenas no Chile, na época do golpe de 1973, talvez estivessem milhares: “Não se sabe ao certo quantos brasileiros estavam no Chile naquela ocasião. Fala-se em várias centenas ou mesmo milhares, que para lá se haviam dirigido, ao longo dos três anos de governo da 'Unidad Popular', para escapar da repressão no Brasil" (Brasil, 2014a, p. 238). Com o golpe liderado pelo General Pinochet, gerou-se nova onda de exilados na América Latina.

Tampouco há um número confiável dos estrangeiros que vieram ao Brasil a partir da abertura política, clandestinamente ou não, fugindo da repressão política em seus países.

Essa significativa lacuna na pesquisa social e na memória do país estaria a ser abordada pela literatura brasileira deste século, considerando que a ditadura militar logo deixaria de ser um assunto importante para a literatura brasileira a partir do fim dos anos 1980? Aparentemente refletindo um movimento maior na sociedade brasileira, de soterrar as questões de justiça de transição, os escritores aparentemente deram o assunto por resolvido poucos anos depois da redemocratização.

Entendemos a justiça de transição de acordo com a definição chancelada pela Organização das Nações de Unidas (UN, 2006), de conjunto de medidas, após certo Estado sair de conflitos ou de regimes autoritários, para apuração e sanção de graves violações de direitos humanos, iniciativas de memória e verdade, de reparação aos atingidos e de reforma das instituições.

A posse do primeiro presidente civil, José Sarney, em 1985, depois dos governos militares, não solucionou o legado autoritário: as graves violações de direitos humanos da ditadura militar brasileira não haviam sido apuradas, muito menos punidas; os desaparecidos não haviam sido encontrados; não havia sido estimado o número de vítimas de genocídio entre os povos indígenas. O silenciamento desses crimes refletiu-se na literatura: Jaime Ginzburg, em artigo que compara o conto "Os sobreviventes", de Caio Fernando Abreu (1982), com uma crônica sobre a busca dos desaparecidos políticos, escrita por Luís Fernando Veríssimo em 1995, criticou com razão o segundo escritor por "redução da gravidade do assunto" (Ginzburg, 2009, p. 563), o que parece ter sido uma tendência da época no Brasil.

A atuação de alguns grupos organizados, como a Comissão de Familiares de Mortos e Desaparecidos Políticos, fez com que o assunto não fosse esquecido no campo da política e, já nos anos 1990, foram possíveis alguns avanços, como a aprovação da Lei dos Desaparecidos Políticos (Lei $\mathrm{n}^{\circ}$ 9.140, de 4 de dezembro de 1995), que instituiu a Comissão Especial de Mortos e Desaparecidos Políticos (CEMDP). A Comissão de Anistia foi criada em 2003 a partir da Lei ${ }^{\circ}$

\footnotetext{
${ }^{1} \mathrm{O}$ banimento foi introduzido pelo Ato Institucional $\mathrm{n}^{\mathrm{o}} 13$, de 5 de setembro de 1969. O Ato Institucional $\mathrm{n}^{\mathrm{o}} 14$, de 5 de setembro de 1969, modificou a Constituição para "constitucionalizar" essa medida. O caráter autoritário dessa medida evidenciava-se pelo fato de que a vedação do banimento já era considerada na época uma garantia fundamental no direito brasileiro.

${ }^{2}$ Este lema foi revivido pelo Sistema Brasileiro de Televisão (SBT) após a vitória do então candidato Jair Bolsonaro à Presidência da República, o que se adequava com a eleição de um defensor da ditadura, da tortura e dos privilégios militares. Depois de críticas, a rede de televisão retirou o lema de circulação (SBT..., 2018), porém ele foi adotado por vários perfis de apoio a Bolsonaro nas redes sociais, o que se explica pela trajetória daquele candidato de elogio à ditadura e a seus agentes.
} 
10.559, de 13 de novembro de 2002, com o fim de reparar os anistiados políticos. Em 2010, ação proposta pela Comissão de Familiares levaria à condenação do Estado brasileiro no Caso da Guerrilha do Araguaia (Gomes Lund e outros vs. Brasil), o que propiciaria a instalação da Comissão Nacional da Verdade em 2012.

Rebecca Atencio (2014) sustenta que, nesse início de século, formou-se um novo ciclo cultural de memória no Brasil. Em Memory's turn, ela aponta como obra literária desse novo ciclo o livro de Fernando Bonassi, Prova contrária, publicado em 2003, que parte da experiência da CEMDP para criar a personagem de um falso desaparecido.

Apenas na primeira década do século a literatura brasileira voltou a tratar desse período (Domeneck, 2014). Seligmann-Silva sustenta que o tema sofreu um recalque em razão de sua natureza de trauma:

Poderíamos ainda nos perguntar o porquê dessa sua volta ao trauma, mas antes é importante lembrar que no Brasil esse tratamento do período da ditadura militar foi recalcado durante décadas. Com exceção dos últimos meses, marcados pela ação da Comissão de Verdade (instalada em maio de 2012 para tratar de crimes cometidos contra os direitos humanos de 1946 a 1988 no Brasil), até recentemente, o tratamento desse tema era absolutamente recessivo na mídia, no governo e no cotidiano brasileiro de um modo geral. No Brasil ocorreu uma privatização do trauma: apenas os familiares e pessoas próximas às vítimas, além dos próprios sobreviventes, se interessaram por esse tema e investiram na sua memória (Seligmann-Silva, 2014, p. 30).

Este artigo tem como objetivo analisar essa questão em obras desse novo ciclo cultural de memória com foco nos exílios e deslocamentos forçados relacionados à ditadura militar. Se os anos 1980 viram a emergência de romances que buscavam "repensar o patrimônio cultural brasileiro a partir do tema da imigração" (Tonus, 2007, p. 1), esse novo olhar pôde cruzar-se no século XXI com o ciclo de memória cultural que retomou os anos de autoritarismo e seu legado? Alguns autores, de fato, fizeram-no, e este artigo concentra-se na análise de obras de Julián Fuks e Francisco Maciel.

\section{Julián Fuks, a justiça de transição no Brasil e na Argentina e o espaço da família}

No romance $A$ resistência, de Julián Fuks, os percursos familiares relacionam-se à história política do continente. Eurídice Figueiredo (2017, p. 112) enquadra o autor entre os "filhos do exílio", em razão de os pais de Fuks serem militantes políticos argentinos que deixaram seu país por causa do golpe militar de 1976. Escolheram vir ao Brasil por causa do processo de abertura política iniciado pelo general Geisel.

No romance, o personagem e narrador Sebastián é brasileiro, mas seus pais são argentinos e ele tem um irmão adotivo que nasceu naquele país. Há problemas de relacionamento desse irmão com a família; o protagonista resolve escrever sobre isso e, por esse motivo, decide viajar para a Argentina, coisa que o irmão nunca fez. Um dos impasses a que chega é o de entrar na sede das Mães da Praça de Maio (Fuks, 2015, p. 19); seu irmão seria filho biológico de desaparecidos políticos? Muitos filhos de oponentes políticos foram sequestrados pelos militares argentinos e entregues a outras famílias para adoção.

Essa questão, bem como o da fuga dos pais, militantes de esquerda, da Argentina para se estabelecerem no Brasil, enquadra essa história na história recente do Cone Sul, das ditaduras militares e da transição política.

Já no capítulo 7 do livro de Fuks, põem-se em tensão explícita história e memória. A memória que ele detém, no entanto, não é a dos pais, nem mesmo da Argentina, onde ele não nasceu, e tampouco pode compartilhar dos valores políticos dos pais: "Tenho a idade que meu pai tinha aquela época - o bastante para saber que as armas dele não são as minhas" (Fuks, 2015 , p. 38). Ele tenta relembrar as conversas dos pais sobre o passado militante. Essa memória dos sussurros e dos detalhes incompletos e contraditórios que ele não viveu - "Sei e não sei que meu pai fez treinamento em Cuba, sei e não sei que jamais desferiu um tiro com alvo certo" (Fuks, 2015, p. 40) - é bem a questão do testemunho desse filho brasileiro, que não se reconhece 
na antiga militância dos seus pais argentinos, que ficou para trás mesmo para eles. Sebastián declara seu mal-estar ao imaginar armas debaixo da cama de seu pai; sempre foi "infenso a esses objetos", e diz, agora que está a escrever o livro em que esse passado dos pais é retomado:

Agora penso nessas armas e não entendo a euforia que sinto, a vaidade que me acomete, como se a biografia do meu pai em mim se investisse: sou o filho orgulhoso de um guerrilheiro de esquerda e isso em parte me justifica, isso redime minha própria inércia, isso me insere precariamente numa linhagem de inconformistas (Fuks, 2015, p. 38).

Perto do fim do romance, em capítulo explicitamente metalinguístico, há uma discussão de Sebastián com seus pais, que leram o livro (que é e não é o que estamos a ler) e não gostaram da forma como foram retratados como militantes ingênuos - uma das ingenuidades seria justamente esconder armas debaixo da cama. Ele retruca que a história deles é realmente estranha e que omitiu passagens "porque nenhum leitor toleraria: como aceitar que tenham voltado à Argentina em pleno regime, clandestinos e vulneráveis, como aceitar que tenham se arriscado tanto para tentar adotar uma menina?" (Fuks, 2015, p. 136). A diferença política entre as duas gerações, dos pais e do filho, escancara-se.

O capítulo 18 narra a tentativa de Sebastián de visitar o apartamento em que os pais viveram em Buenos Aires. Ele explica com muita reticência ao porteiro do prédio a razão de querer ver o apartamento - vê-se a resistência do personagem em tratar do assunto -, até que revela que o casal que lá viveu eram seus pais, e o bebê, seu irmão. O porteiro compreende e afirma "Ah, una más, una memoria más de los setenta" (Fuks, 2015, p. 58) e lhe permite entrar. O corpo, dele, no entanto, responde com a "paralisia", que seria a "integridade" possível naquele momento.

Algo semelhante ocorre em Procura do romance, romance em que Fuks já apresentava um protagonista brasileiro chamado Sebastián. O personagem viaja para Buenos Aires em busca de tema para seu romance. Depois de participar da cerimônia semanal das Mães na própria Praça de Maio, apesar de não entender bem o que está a ser dito, "sente algo como um pertencimento" (Fuks, 2011, p. 128). Trata-se de uma ilusão: o acontecimento precipita uma crise psicológica no capítulo seguinte, o penúltimo do livro, que o remete à infância. As palavras "não acudiram" e volta a sensação de "querer sair do apartamento e da cidade e do país inteiro" (Fuks, 2011, p. 136). É o que ele faz no final, sentindo "uma derrota que, se não justifica ante os outros, ao menos o devolve aos limites de si mesmo" (Fuks, 2011, p. 142).

No romance seguinte, A resistência, o caráter político dessa derrota explicita-se. No entanto, tratar-se-ia realmente de mais uma memória dos anos 1970, segundo a expressão do porteiro do prédio em que os pais viveram, como outras que foram concebidas na Argentina? Seria interessante comparar com o caso dos escritores argentinos da mesma geração que Fuks. Na Argentina, a geração dos filhos dos mortos e desaparecidos políticos criou em 1995 sua própria rede para exigir justiça: os H.I.J.O.S. (Hijos y Hijas por la Identidad y la Justicia contra el Olvido y el Silencio). As demandas por justiça haviam sido paralisadas judicialmente por leis de anistia. $\mathrm{Na}$ Argentina, depois das anistias limitadas de Alfonsín, outro presidente civil, Carlos Menem, concedeu indultos na década de 1990 aos agentes de graves violações de direitos humanos que haviam sido condenados.

As Mães e Avós da Praça de Maio continuavam com suas ações militantes contra a impunidade dos genocidas. Entre os meios empregados pelos H.I.J.O.S. para exigir justiça estavam os chamados "escraches" aos agentes e colaboradores da repressão bem como a literatura, tanto escrita quanto em performance (Tavernini, 2018). Nasceu naquele momento uma literatura engajada que participou da mobilização social que levou, finalmente, à anulação das leis de anistia.

A memória, após a ditadura, ganhou uma função política, como lembrou Beatriz Sarlo a respeito da América Latina após o ciclo de ditaduras dos anos 1960 a 1980:

A memória foi o dever da Argentina posterior à ditadura militar e o é na maioria dos países da América Latina. O testemunho possibilitou a condenação do terrorismo de Estado; [...] Como instrumento jurídico e como modo de reconstituição do passado, ali donde outras fontes foram destruídas pelos responsáveis, os atos de memória foram uma peça central da transição 
democrática [...] Nenhuma condenação teria sido possível se esses atos de memória, manifestados nos relatos de testemunhas e vítimas, não tivessem acontecido (Sarlo, 2007, p. 20).

Os atos de memória integraram o fundamento social das demandas por justiça de transição. Contudo, que tipo de memória esses H.I.J.O.S. tinham da ditadura, visto que muitos nasceram após o golpe ou eram muito pequenos quando ele ocorreu? Seria o caso de uma pós-memória segundo postulou Marienne Hirsch para a arte sobre o Holocausto?

A pós-memória descreve, segundo Hirsch, a relação da geração seguinte com um trauma coletivo; as experiências da geração anterior foram transmitidas de forma tão profunda que parecem constituir uma memória própria; trata-se, de uma memória mediada pelo "investimento imaginativo, pela projeção e criação" (Hirsch, 2008, p. 107).

Sarlo, em relação à Argentina, criticou o conceito de pós-memória, afirmando que o que existem são "formas de memória que não podem ser atribuídas diretamente a uma divisão simples entre memória dos que viveram os fatos e memórias do que são seus filhos" (Sarlo, 2007, p. 115). Pareceme também que a produção literária dos H.I.J.O.S., em especial a poesia dos autores que gravitam em torno da coleção Los Detectives Salvajes, ${ }^{3}$ não corresponde a uma pós-memória:

[...] a experiência dos hijos permite-lhes dizer que apresentam suas próprias memórias sobre o terror de Estado: o fato de terem perdido os pais e outros parentes, de terem tido, muitas vezes, sua identidade negada ou subtraída marcou-lhes a infância e representa a marca do terror de Estado em sua história pessoal, inscrita nessa história coletiva. Nesse sentido, suas subjetividades também foram configuradas pelo terror, e isso os autoriza a falar como testemunhas diretas da ditadura (Fernandes, 2015, p. 130).

O romance de Fuks difere muito da literatura dos H.I.J.O.S. nesse aspecto, e está mais próximo do conceito da pós-memória; creio que essa diferença diz respeito às dessemelhanças dos processos de justiça de transição na Argentina e no Brasil. Uma das diferenças se dá no fato de que o caráter militante que pode ser encontrado na literatura dos H.I.J.O.S. não está presente neste romance brasileiro, em razão do tipo de inscrição desta memória na história política: "Jamais quereria ter uma arma em minhas mãos, e dizê-lo também é uma ação, também constitui uma história política” (Fuks, 2015, p. 109).

É bem conhecida a origem das Mães de Maio e sua luta por descobrir o paradeiro de seus filhos desaparecidos, complicada ainda pelo sequestro de crianças pelos militares argentinos.

Essas graves violações de direitos humanos já eram conhecidas no Brasil durante a última ditadura militar. Quando o ditador Videla visitou o Brasil, houve protestos; em São Paulo, ocorreu um ato em 22 de agosto de 1980 no Largo de São Francisco. O panfleto que servia para convocar ao evento chamava Videla de "um dos maiores carrascos de todos os tempos na América Latina" e acrescentava que "Ninguém aceita que venha ao Brasil o ditador responsável por milhares de mortos desaparecidos; presos políticos, e inclusive pelo desaparecimento de pelos menos doze brasileiros em solo argentino" (Fora..., 1980).

No Brasil, porém, apesar dos menores que foram perseguidos pela ditadura, a mobilização da sociedade civil brasileira também foi mais restrita do que nesse outro país. O destino dos autores das graves violações de direitos humanos também foi outro: Videla foi condenado e preso, vindo a morrer de causas naturais em sua cela, em 2013, aos 87 anos. Diferentemente da comissão argentina - a Comisión Nacional sobre la Desaparición de Personas (Conadep), que concluiu o relatório Nunca más em 1984 -, nada houve de parecido no Brasil, mesmo com a Comissão Nacional da Verdade, que surgiu 27 anos depois do fim da ditadura.

\footnotetext{
${ }^{3}$ A coleção, cujo nome homenageia Roberto Bolaño, nasceu em 2007 a partir de proposta de José María Pallaoro, editor dos Libros de la Talita Dorada, a Julián Axat e Juan Aiub, para publicar os poemas inéditos do pai de Juan, Carlos Aiub, uma das vítimas da ditadura (Tavernini, 2018, p. 74). Axat elaborou então o projeto de uma coleção para resgatar autores que foram vítimas do terror de Estado, bem como publicar escritores contemporâneos que dialogam com esse tema e essas vozes que foram caladas. Cito-o: "El proyecto LDS [Los Detectives Salvajes] que co-dirijo rescata voces literarias amputadas del pasado y las conecta con las voces de hoy que están contando lo que les pasó o lo que vieron sus padres en aquella época. La poesía es motivo para construir puentes entre generaciones dislocadas. El soporte, documentos literarios inéditos o hallados que cicatrizan heridas al editarse como libros que entran en circulación” (Axat, 2010, p. 251).
} 
Essas diferenças encontram expressão no romance de Fuks. O impasse do narrador diante da sede das Mães da Praça de Maio mostra essa relutância em face do caráter político dessa história, e o lugar central dos espaços privados no livro enfatiza o relativo acanhamento da esfera pública. Em $A$ resistência, esses lugares aparecem especialmente no trauma da expulsão do quarto do irmão, e o acidente que ocorre logo em seguida, com a imagem do irmão "se partindo em estilhaços".

A paralisia de Sebastián relaciona-se ao difícil andamento do próprio processo de justiça de transição no Brasil (e que permitiu em 2018 a eleição de um governo que nega o caráter criminoso da ditadura militar e elogia torturadores). O porteiro, em Buenos Aires, falou de "una más" memória dos anos 1970. No entanto, no Brasil, o slogan do Nunca Mais parece ter sido dado justamente à memória, e não aos crimes contra a humanidade. Fuks expressa essa disparidade entre os dois países no próprio caminho de escrita do livro, que vai sendo preparado pelo narrador: a obra desanda, não sai como ele quer, o peso do terror, da tortura e dos desaparecimentos vai escapando de Sebastián.

Com efeito, menciona-se uma desaparecida argentina no capítulo 25, Martha María Brea, jovem psicóloga amiga da mãe do protagonista, identificada apenas em 2010: "sua ausência morava na nossa casa" (Fuks, 2015, p. 78). São mencionados a tortura sofrida por outros amigos dos pais, o malestar do protagonista diante das Mães de Maio, a "súbita vergonha" diante da sala das Avós no "museu da memória" (Fuks, 2015, p. 93) e a sensação de "fracasso" (destacada no capítulo 32) que o persegue ao escrever o livro, bem como a desorientação súbita em Buenos Aires, cidade onde se localizar é tão fácil (capítulo 44); "não pude entrar na sede das Avós, fiquei do lado de fora vendo o que acontecia, e o lamento que agora me sobrevém não parece mero capricho" (Fuks, 2015, p. 130).

A dificuldade de escrever o livro pretendido inscreve-se na história política. Edson Teles postulou que havia dois tipos de silêncio sobre a ditadura na sociedade brasileira:

Parece-nos haver dois tipos de silêncio no pós-ditadura brasileiro: no primeiro, em um ato de sanidade interior, refaz-se o percurso do vivido no silêncio do pensamento e da impossibilidade de narrar o que não se compreende; no outro, o "silêncio do não dizer", que se constitui a partir do exterior (a ausência da esfera pública), equivalente à desresponsabilização de cada sujeito, ao não assumir ações e discursos críticos acerca dos anos de repressão sob a ênfase de valores éticos (Teles, 2015, p. 103).

$\mathrm{O}$ bloqueio com que se depara o narrador parece próximo do primeiro tipo de silêncio. $\mathrm{O}$ livro parece fazer esse percurso senão de cura, de sanidade, que envolve compreender (o) que não pode narrar, refazendo, na comparação com a Argentina, os impasses do processo de justiça de transição no Brasil: tais impasses impedem que o livro se torne a narrativa sobre desaparecimentos antes planejada. Sebastián afirma que sabe que escreve o seu fracasso, e ele também é de caráter político.

Há vários sentidos de resistência nesse livro, políticos e psicanalíticos. Um deles é a resistência ao próprio processo de justiça de transição no Brasil, o qual parece sofrer um bloqueio em relação à Argentina, que teve ditadores, torturadores e assassinos julgados, condenados e presos. Julián Fuks, por sinal, indagado pelo Deutsche Welle sobre as "diferenças em como cada país [Argentina e Brasil] lida" com o passado autoritário, respondeu: "É uma diferença abismal entre a Argentina e o Brasil, quase dois polos opostos na questão de lidar com a própria memória" (Fuks, 2018).

A comparação entre os dois países é assunto também de outro escrito do autor e tratada no âmbito da família, assim como no romance. No conto "O jantar", um personagem também chamado Sebastián, brasileiro filho de pais que tiveram de migrar ao Brasil por causa do golpe na Argentina, visita uma tia argentina que defende a ditadura. Ela se queixa da presidenta Cristina Kirchner, das Mães e das Avós da Praça de Maio e dos julgamentos dos genocidas. Ressalva, contudo, o país do sobrinho: "Só não ocorre o mesmo no Brasil porque os militares de vocês sempre foram muito brandos, não havendo qualquer culpa a imputar-lhes. Morreram alguns aqui, ou no Chile, até no Brasil? Morreram. Mas o contexto faz de muitas mortes atos justificáveis" (Fuks, 2016, p. 26). Para a tia simpática aos genocidas e oposta à justiça de transição, o Brasil está em situação melhor, visto que o negacionismo histórico prevalece em relação aos crimes da ditadura.

No penúltimo capítulo do romance, Sebastián diz da família: "chegamos a ser mais brasileiros" (Fuks, 2015, p. 134). A história política do malogro brasileiro no campo da justiça de 
transição marca assim a memória dessa família, e orienta a escrita do livro que o protagonista deseja escrever - e que é o livro que o leitor tem nas mãos. Ele descobre, nessa nova "procura do romance", que a obra tem que tomar outro rumo, familiar e lírico, como conta depois do acidente de infância em que fraturou o braço: "nessa noite fui eu quem quis dormir ao seu lado, juntei o meu colchão ao dele, apoiei sobre seu peito o braço que me restava" (Fuks, 2015, p. 127).

\section{Francisco Maciel, o racismo na ditadura e a diáspora como forma literária}

Durante a ditadura militar, houve quem tomasse consciência de sua identidade negra por causa da perseguição política e do exílio. O escritor e historiador Joel Rufino dos Santos, que militou na Ação Libertadora Nacional (ALN), grupo guerrilheiro criado por Carlos Marighella, exilou-se no Chile depois do AI-5. Ele foi "nomeado tesoureiro da caixa de ajuda dos exilados pobres, que eram muitos" e, ao andar pelas ruas, "era assediado por homens, mulheres e crianças que pediam para passar a mão no meu rosto ou nos meus braços, para ver se largavam tinta. Realmente aí senti que era diferente" (Santos, 2009, p. 29). O cineasta Zózimo Bubul, que teve diversos amigos presos depois de 1970, foi para os Estados Unidos para não ter o mesmo destino e, naquele país, descobriu o movimento negro: "quando saí daqui eu achava que não tinha história, eu não sabia direito que eu era preto. Quando encontrei os americanos e eles me diziam 'Eu sou preto, black, black power', aí senti a força da palavra black" (Bubul, 2009, p. 241).

A ditadura militar incrementou a repressão e a vigilância política sobre os movimentos sociais, inclusive os da população negra. O Centro de Informações da Aeronáutica (Cisa), sobre Abdias Nascimento, não deixou de registrar o obstáculo que a ditadura era para a militância: "sentindo-se tolhido para desenvolver suas atividades no Brasil, resolveu aceitar o cargo de professor catedrático na Universidade do Estado de Nova Iorque, em Buffalo, por considerá-lo um trampolim para fazer o movimento negro chegar aos quatro cantos do mundo" (Brasil, 1978a, p. 1; Brasil, 1978b, p. 1). Abdias Nascimento era qualificado por esse órgão de informações como a "figura de maior projeção do movimento racista negro no Brasil" (Brasil, 1978b, p. 1), pois o regime negava a legitimidade da luta contra a discriminação racial, tratando as lutas contra o racismo como se fossem manifestações racistas e importadas, e não como manifestações legítimas dos negros brasileiros.

Abdias Nascimento, que deixou o Brasil em 1968 por causa da repressão política, escreveu no exílio, em 1977, seu célebre estudo sobre o genocídio do negro brasileiro: "Não é exagero afirmarse que, desde o início da colonização, as culturas africanas, chegadas nos navios negreiros, foram mantidas num verdadeiro estado de sítio" (Nascimento, 2016, p. 124). Naquele trabalho, ele se confirmou "não como representante do Brasil, mas como um sobrevivente da República dos Palmares" (Nascimento, 2016, p. 46). O autor se aproximava, assim, das abordagens da diáspora, ${ }^{4}$ o que leva a pensar o racismo no Brasil como uma forma de desterro para os negros.

Essa difícil relação entre nacional e estrangeiro no tocante aos movimentos negros e ao racismo institucional, que se tornou mais aguda durante a ditadura militar tendo em vista a repressão política, que considerava a luta contra o racismo como algo antinacional, é um dos temas do romance O primeiro dia do ano da peste, de Francisco Maciel, cuja história se passa principalmente durante o governo Médici. Um estudante estadunidense de antropologia, William, louro e de olhos azuis, morava em Niterói e pesquisava a presença do negro na poesia brasileira. Ele namorava Leila, uma mulher negra brasileira, e conheceu Aloísio Cesário (conhecido como AC), um músico negro que se dizia africano, embora fosse brasileiro. William acabou preso por tráfico de drogas em abril de 1972, saiu com problemas psíquicos da prisão, fugiu de um sanatório e deixou diversos escritos atrás de si. Uma das identidades que ele assumiu antes da prisão foi a de guerrilheiro:

Durante algum tempo eu cheguei a pensar que ele estava envolvido na resistência armada à ditadura militar. Entre os grupos que frequentávamos a discussão política estava sempre em pauta e todos éramos teoricamente de esquerda. [...] Creio que foi o próprio AC que espalhou o boato de que ele pertencia a uma das organizações da

\footnotetext{
${ }^{4}$ Deve-se lembrar que "bem antes de escrever para o Journal of Black Studies, a visão de Nascimento já adotava uma abordagem afrodiaspórica" (Miles, 2017, p. 126).
} 
resistência, tendo participado de assaltos a banco, desapropriando os "capitalistas safados e entreguistas" e investindo na libertação do povo brasileiro. Ele manteve essa máscara por algum tempo (Maciel, 2001, p. 16).

O romance se inicia com uma introdução de William explicando como conheceu AC e decidiu publicar os escritos do antigo amigo, que possuem teor autobiográfico não só pelo conteúdo, mas pelo caráter progressivamente desconexo do material coligido, a acompanhar a piora do estado psíquico do autor. A condição de estrangeiro de AC é negada em termos de registro de nascimento, mas é expressa pelos escritos do personagem como condição cultural determinada pelo racismo, que parecem entender a diáspora como condição imposta ao afrodescendente.

Os textos de AC apresentam personagens que passam pela experiência de migrante. Um deles, Quirino Tembê, decide tornar-se um "negro integral", o que exige deixar o Brasil, em uma aparente tentativa de desfazer a diáspora. Nessa jornada, ele passa por diversos países como Bolívia, Peru, Estados Unidos (onde é preso por participar de uma revolta do movimento negro daquele país, mas foge da prisão), França, Índia, China, Vietnã, Coreia do Norte, Japão , além do continente africano, que o desilude: "A África até podia não ser um inferno, mas certamente era um céu saqueado" (Maciel, 2001, p. 52).

Decepcionado, volta para o Brasil onde encontra um casal de expatriados africanos, que receberam formação universitária na Europa e não mais se adaptaram a seus países. Chegaram a integrar o ministério, mas não conseguiram implantar as reformas modernizadoras que mudariam os costumes tradicionais. Janime Touré, a esposa, revela:

No meio da tradicional família africana, vendo a disputa das mulheres entre si e os velhos ódios adormecidos, descobriu que não teria mais condições de ser uma africana. Também não seria europeia, já que a Europa era apenas a rama da árvore e a raiz já estava morta. Nem Europa nem África: tinha perdido o jogo (Maciel, 2001, p. 39).

Há uma situação parecida no conto "Entre dois mundos", que Francisco Maciel publicou pouco antes. Um personagem negro também chamado de Aloísio Cesário ou AC frequenta cursos de alemão, e seu caso com a literatura nessa língua era uma das razões para sentir-se "entre dois mundos". O conto é repleto de referências literárias a autores como Rilke, Goethe, Enzensberger. Nesta passagem de zombaria racista, um personagem que é pastor evangélico (com o nome de um dos heterônimos de Fernando Pessoa, que tem como iniciais AC) pergunta-lhe:

- Por que não se converte ao candomblé, senhor? - riu Álvaro de Campos. - As suas raízes estão em Angola, senhor, e não em Weimar. Para que fugir de Frankfurt se você mora em Biafra, senhor? Já esteve em Casablanca, senhor? E Johanesburgo, sabe onde fica, senhor?

- A África é minha pele, senhor (Maciel, 2000, p. 25).

A África é somente sua pele, quer dizer, e ele fica "entre dois mundos", sem lugar.

No romance, a história dos expatriados africanos que fracassaram em reformar seu país conclui-se com a constatação de que "não há retorno ao país natal" (Maciel, 2001, p. 39). A diáspora não pode ser desfeita. Nesse trecho, como em outras passagens do romance, temos uma alusão à Unheimlichkeit de Heidegger, no mesmo sentido que Stuart Hall emprega para tratar das identidades deslocadas na modernidade. Hall refere-se às diferentes identidades dos migrantes caribenhos no Reino Unido, que sentem dificuldade em se "religar" às comunidades de origem:

Muitos sentem falta dos ritmos de vida cosmopolita com os quais tinham se aclimatado. Muitos sentem que a "terra" tornou-se irreconhecível. Em contrapartida, são vistos como se os elos naturais e espontâneos que antes possuíam tivessem sido interrompidos por suas experiências diaspóricas. Sentem-se felizes por estar em casa. Mas a história, de alguma forma, interveio irrevogavelmente. Esta é a sensação familiar e profundamente moderna de des-locamento, a qual - parece cada vez mais - não precisamos viajar muito longe para experimentar. Talvez todos nós sejamos, nos tempos modernos - após a Queda, digamos - o que o filósofo Heidegger chamou de unheimlicheit - literalmente, "não estamos em casa" (Hall, 2003, p. 27). 
Essa sensação permeia os escritos coligidos de AC. Um deles, o mais longo, "O primeiro dia do ano da peste" (que dá título ao romance de Francisco Maciel), apresenta um protagonista negro que, como $\mathrm{AC}$, vive entre brancos durante a ditadura militar, o que gera desconforto: "Devia ter me acostumado com a ideia de ser um ou outro criolo no meio de brancos", e desabafa: "hoje estou estrangeiro" (Maciel, 2001, p. 43).

Esse personagem foi militar, mas desistiu da carreira por causa do racismo institucional das Forças Armadas: "O capitão me aconselhou a seguir carreira. Eu disse que não seguia porque nunca tinha visto um general crioulo e eu não seria o primeiro" (Maciel, 2001, p. 61); ele indaga se sua vida teria sido diferente em outro país: "No Haiti eu seria um general ou o chefe de polícia? General em Angola ou guerrilheiro em Moçambique? Generais de mim, trégua!" (Maciel, 2001, p. 65). A ideia de que poderia ter galgado postos mais altos se vivesse em um país africano, ou no Haiti, reforça seu sentimento de estrangeiro. No Brasil, por ser negro, não poderia sentir-se plenamente cidadão, mesmo com os amigos brancos como Lino, o intelectual que está entre os "anti-anticomunistas" nesse tempo de ditadura militar:

Suporto o papo do intelectualzinho de merda.

- Sabe o que está fodendo o mundo ocidental?

- Não.

- A perda do instinto animal.

- E o que eu tenho a ver com isso?

- Tudo. Você é instinto, anima, maná, ritmo.

Você é negro, ele não diz (Maciel, 2001, p. 74).

Outra personagem branca, Gininha, uma professora de história, quer explicar-lhe o universo da cultura negra, e ele reage: "Você é branca e quer me dar uma consciência de negro. Se eu digo que não preciso de sua ajuda você se aborrece" (Maciel, 2001, p. 79). Nem dos militares nem dessa esquerda branca universitária ele poderia esperar um reconhecimento pleno como cidadão, o que condiz com as críticas feitas pelos movimentos negros durante a ditadura no Brasil em relação à invisibilização da discriminação racial. ${ }^{5}$

Personagens migrantes aparecem no romance seguinte de Francisco Maciel, Não adianta morrer. Aqui, eles não são metáfora da condição do negro brasileiro. Trata-se de angolanos refugiados no Brasil do século XXI. No primeiro capítulo, eles são apresentados pelo narrador. Descobriram uma falha do sistema que lhes permite telefonar de graça para seu país de um telefone público. No entanto, foram reprimidos pela polícia militar, que considerou suspeita uma aglomeração de negros durante a madrugada:

Levaram uma dura da PM, um bando de negros em volta de um orelhão às duas da manhã não pode ser uma coisa boa. [...] Vieram fugidos da guerra civil e da herdada miséria colonial, mas nunca foram escravizados, não foram traficados em navios negreiros. São livres de qualquer mancha escrava. Não foram arrancados pela raiz (Maciel, 2017, p. 16).

Eles não são fruto da diáspora causada pela escravidão, o que não os impede de serem discriminados no Brasil e associados ao crime, assim como é feito com os negros brasileiros: "Os angolanos vieram fugidos da guerra civil e da miséria colonial para servir de mulas ou como soldados do tráfico, é o que se diz. Os chineses ralam duro como reféns da máfia chinesa, é o que se fala. Mas hoje os angolas só estão fazendo hora na lanchonete dos chinas" (Maciel, 2017, p. 87). Não há uma identidade negra comum que congregue os refugiados angolanos e os cariocas: "Não querem ser confundidos com os negros daqui, que não gostam deles" (Maciel, 2017, p. 88). O choque cultural, com efeito, dificulta a comunicação: "Os angolas se fecham em copas quando o funkeiro pixaim louro oxigenado bate palmas, rodopia e rapeia: 'Aí, Maria, fecha a caixa, pega a grana, vamos subir o morro, vou te dar uns amassos, lá na minha caxanga, vamos subir o morro'" (Maciel, 2017, p. 89). A menina oriental recusa o avanço amoroso do jovem brasileiro, e os angolanos não entendem se se trata de briga ou de brincadeira.

\footnotetext{
${ }^{5}$ Aqui, lembremos da conhecida crítica feita por Lélia González, que "denunciou que a própria esquerda esquecia a discriminação racial, praticando o 'racismo por omissão', título de artigo que publicou em 1983 sobre o programa do Partido dos Trabalhadores (PT), partido a que ela pertencia na época”' (São Paulo, 2015, p. 17).
} 
Essa história com os angolanos aparece entre dezenas de outras no romance; em todas elas, destacam-se os personagens negros. Em geral, são tratados como perigosos ou suspeitos pelas instituições: favelas são comparadas a "Vietnames" por causa de Che Guevara (Maciel, 2017, p. 267), em continuidade à doutrina de segurança nacional da ditadura militar.

Apesar de alguns capítulos poderem ser lidos independentemente, não se trata de uma reunião de contos, tampouco de um romance construído a partir da técnica do conto como Ivan Ângelo fez em A festa. Este romance de Francisco Maciel apresenta outro princípio formal, pois mistura gêneros, como poesia, libreto de ópera, teatro e samba-enredo, e não segue uma narrativa linear: uma situação é dada no primeiro capítulo e diversas histórias se seguem, mas que cronologicamente variam bastante: há aquelas que se passam antes do que ocorre no início, outras se passam depois. Não há um centro narrativo único.

O primeiro capítulo narra como o jovem Dafé, que pertence a um bando criminoso, caminha, sem saber, para uma emboscada. Ele passa pelos migrantes angolanos e o narrador se refere pela primeira vez à chuva de cinzas de cadáveres que caiu no bairro do Estácio, no Rio de Janeiro. O capítulo termina depois de ele ser alvejado e perder a consciência.

A unidade do livro é dada não pelos personagens que retornam, embora isso ocorra, mas pelos motivos temáticos de que são geradas as histórias: o primeiro, o de que os jovens retratados têm "prazo de validade", pois serão abatidos seja por colegas, seja pelo Estado. O segundo, o da chuva de cinzas de cadáveres queimados que cai na rua Maia de Lacerda, associada ao conceito de maya hindu: a ilusão da realidade do mundo, do hinduísmo, é comparada aos planos de vida dos jovens que logo morrerão.

As histórias partem desses motivos, que estão fortemente relacionados no fundo comum do genocídio da juventude negra. Algumas delas se cruzam, outras não, e envolvem questões de gênero, orientação sexual, diferenças de classe, de gerações: temos o Vovô do Crime e o jovem Dafé, o pai que foi ladrão e a filha que trabalha no Movimento Negro, o casal inter-racial do negro Xande e o branco Bastian; Guile Xangô, que deseja exorcizar os espíritos dos jovens jogados da pedreira; Denise, jovem que sofre um estupro coletivo em um conjunto habitacional. Não há, evidentemente, uma única identidade negra, e a identidade não é problematizada no romance apenas no tocante à questão racial.

Nesse sentido, o livro de Francisco Maciel corresponde à afirmação de Stuart Hall de que se deva dar a "atenção criativa" não à homogeneidade, mas à "diversidade da experiência negra" (que é multiplicada pela diáspora), o que não se resume a apreciar as diferenças entre e dentro de comunidades: "A questão é que, em razão de não sermos totalmente constituídos por nossas diferenças raciais, somos sempre diferentes, negociando diferentes tipos de diferenças - de gênero, de sexualidade, de classe" (Hall, 2019, p. 92, tradução nossa).

Francisco Maciel, portanto, adota uma forma narrativa que parece emular a própria diáspora, não só no tema como na estrutura, no tocante à dispersão das vozes e das histórias e sua multiplicidade irredutível, que não poderia ser conformada a uma unidade ou identidade única sem perda artística e política.

\section{À guisa de conclusão: formas literárias e a experiência da transição política}

Os autores analisados adotam abordagens bastante diferentes da questão dos exílios e das migrações na ditadura militar. A história de A resistência, de Julián Fuks, se passa depois da redemocratização na Argentina e no Brasil e se constituiu como pós-memória do filho escritor que deseja reconstruir a memória familiar. Essa tarefa leva-o a viajar para a Argentina, país de onde seus pais migraram. As dificuldades nessa reconstrução apontam os problemas do próprio processo de justiça de transição no Brasil em comparação com o país vizinho. O problema acaba por circunscrever-se ao âmbito da família, confirmando o que Seligmann-Silva (2014) afirma sobre a "privatização do trauma" no Brasil, em contraste com os sucessos já obtidos da ação política na Argentina dessas três gerações cujo nome, no entanto, refere-se à família: das Avós e Mães da Praça de Maio e dos H.I.J.O.S. 
A questão racial não é problematizada no livro de Fuks, o que indica que os personagens são brancos. Em revanche, os dois romances de Francisco Maciel têm protagonistas negros; em O primeiro dia do ano da peste, cuja história se passa, em boa parte, durante o governo Médici, a questão racial é fundamental para a experiência da migração e a tomada de consciência sobre a diáspora: a discriminação racial deixa os personagens sem país, incompreendidos tanto à direita quanto à esquerda.

Não adianta morrer se passa depois da redemocratização; as marcas da ditadura, no entanto, fazem-se bem visíveis no tratamento da população negra e das periferias como inimigas do Estado, o que é estendido aos refugiados angolanos na cidade do Rio de Janeiro. Dessa forma, o romance não está interessado na representação dos crimes do passado autoritário, porém nas continuidades da ditadura em um país levado pela transição política à democracia formal, mas sem que a justiça de transição tenha sido implantada de forma suficiente (o que exigiria mais medidas específicas de combate à discriminação racial).

Outro ponto de originalidade é o fato de a diáspora, em Não adianta morrer, aparecer não apenas como tema, mas também como forma literária, quebrando a linearidade do discurso: as histórias têm em comum dois motivos, ambos vinculados à morte, referida desde o título, e que se apresenta como o horizonte desses personagens marcadas pela discriminação e pela violência. Dessa forma, assim como no romance de Fuks, a forma literária já traz, nela mesma, uma compreensão do processo social a que se refere como tema.

\section{Referências}

ABREU, Caio Fernando. Os sobreviventes. In: ABREU, Caio Fernando. Morangos mofados. São Paulo: Brasiliense, 1982. p. 13-18.

ATENCIO, Rebecca (2014). Memory's turn: reckoning with dictatorship in brazil. Madison: University of Wisconsin Press.

AXAT, Julián (2010). A desobediência biopoética e o direito de resistência. Prisma Jurídico. São Paulo, v. 9, n. 2, p. 241-252, jul./dez.

BRASIL (1978a). Força Aérea Brasileira. Centro de Informações da Aeronáutica. Informação no 975 CISA-RJ. Documento confidencial VAZ.43A.171. Rio de Janeiro: Arquivo Nacional, 9 out.

BRASIL (1978b). Força Aérea Brasileira. Centro de Informações da Aeronáutica. Informação no 277/A-2/IV COMAR. Documento confidencial VAZ.30A.191. Rio de Janeiro: Arquivo Nacional, 16 out.

BRASIL (2014a). Comissão Nacional da Verdade. Relatório. Brasília: CNV. v. 1.

BRASIL (2014b). Comissão Nacional da Verdade. Relatório. Textos temáticos. Brasília: CNV. v. 2.

BRASIL (2014c). Comissão Nacional da Verdade. Relatório. Mortos e desaparecidos políticos. Brasília: CNV. v. 3.

BUBUL, Zózimo (2009). Zózimo Bubul. In: COSTA, Haroldo (Org.). Fala, crioulo: o que é ser negro no Brasil. Rio de Janeiro: Record. p. 238-242.

DOMENECK, Ricardo (2014). A literatura brasileira sob regimes autoritários. Deutsche Welle Brasil, Berlin, 1o abr. Disponível em: http://p.dw.com/p/1BZTM. Acesso em: 10 fev. 2018.

FERNANDES, Pádua (2015). Literatura e justiça: Julián Axat e os desaparecidos na Argentina. In: CEI, Vitor; DAYRELL, João Guilherme; AZARA, Michel Mingote Ferreira de (Org.) A literatura e a vida: por que estudar literatura? Vila Velha: Praia; RCG. p. 109-135.

FIGUEIREDO, Eurídice (2017). A literatura como arquivo da ditadura brasileira. Rio de Janeiro: 7 Letras.

FORA Videla! (1980). 50-Z-00-15337. Acervo DEOPS/SP. São Paulo: Arquivo Público do Estado de São Paulo, 19 ago.

FUKS, Julián (2011). Procura do romance. Rio de Janeiro: Record. 
FUKS, Julián (2015). A resistência. São Paulo: Companhia das Letras.

FUKS, Julián (2016). Os olhos dos pobres. São Paulo: La Sofía Cartonera; Malha Fina Cartonera; Mariposa Cartonera.

FUKS, Julián (2018). "Brasileiro desconhece os riscos de regimes autoritários". Deutsche Welle Brasil, Berlin, 19 jun. Disponível em: https://p.dw.com/p/2zlD4?maca=pt-BR. Acesso em: 13 fev. 2019.

GINZBURG, Jaime (2009). A ditadura militar e a literatura brasileira: tragicidade, sinistro e impasse. In: SANTOS, Cecilia MacDowel; TELES, Edson; TELES, Janaína de Almeida. (Org.) Desarquivando a ditadura: memória e justiça no Brasil. São Paulo: Hucitec. v. 2, p. 557-568.

HALL, Stuart (2003). Da diáspora: identidades e mediações culturais. Tradução de Adelaine La Guardia Resende et al. Belo Horizonte: Editora UFMG; Brasília: Representação da Unesco no Brasil.

HALL, Stuart (2019). Essential essays volume 2: identity and diaspora. Durham: Duke University Press.

HIRSCH, Marianne (2008). The generation of postmemory. Poetics Today, Durham, v. 29, n. 1, p. 103-128, Spring.

MACIEL, Francisco (2000). Entre dois mundos. In: MACIEL, Francisco et al. Entre dois mundos. São Paulo: Estação Liberdade. p. 11-28.

MACIEL, Francisco (2001). O primeiro dia do ano da peste. São Paulo: Estação Liberdade.

MACIEL, Francisco (2017). Não adianta morrer. São Paulo: Estação Liberdade.

MILES, Tshombe (2017). Abdias Nascimento e a tradição intelectual afrodiaspórica: no combate ao racismo. Tradução de João Miguel Lima. Revista de Ciências Sociais, Fortaleza, v. 48, n. 2, p. 106-136, jul./dez.

NASCIMENTO, Abdias (2016). O genocídio do negro brasileiro: processo de um racismo mascarado. São Paulo: Perspectiva.

SANTOS, Joel Rufino (2009). Joel Rufino dos Santos. In: COSTA, Haroldo (Org.). Fala, crioulo: o que é ser negro no Brasil. Rio de Janeiro: Record, p. 28-31.

SÃO PAULO (Estado) (2015). Assembleia Legislativa do Estado de São Paulo. Comissão da Verdade do Estado de São Paulo "Rubens Paiva". Relatório. Perseguição à população e ao movimento negros. São Paulo: Alesp. Disponível em: https:/ / bit.ly/2m1vVEW. Acesso em: 5 fev. 2019. Tomo I, parte II.

SARLO, Beatriz (2007). Tempo passado: cultura da memória e guinada subjetiva. Tradução de Rosa Freire D’Aguiar. São Paulo: Companhia das Letras; Belo Horizonte: Editora UFMG.

SBT ressuscita e mata "Brasil, ame-o ou deixe-o" em vinheta relâmpago (2018). Folha de S. Paulo, São Paulo, Ilustrada, 6 nov. Disponível em: https:// bit.ly/2SRvMjt. Acesso em: 6 fev. 2019.

SELIGMANN-SILVA, Márcio (2014). Imagens precárias: inscrições tênues de violência ditatorial no Brasil. Estudos de literatura brasileira contemporânea, Brasília, n. 43, p. 13-34, jan./jun.

TAVERNINI, Emiliano (2018). Poesía, política y memoria en la Argentina reciente: la colección Los Detectives Salvajes (2007-2015). Tesis (Magíster en Historia y Memoria) - Universidad Nacional de la Plata, Buenos Aires.

TELES, Edson (2015). Democracia e estado de exceção: transição e memória política no Brasil e na África do Sul. São Paulo: Fap-Unifesp.

TONUS, Leonardo (2007). La bâtarde dans les romans de/sur l'immigration au Brésil. In: COLLOQUE INTERNATIONAL DU SEMINAIRE D'ETUDES LUSOPHONES: "La voix des femmes dans les cultures de langue portugaise - Penser la différence", 26-27 mars, Université Paris-Sorbonne). Actes... Paris: Université ParisSorbonne. Disponível em: http://crimic-sorbonne.fr/img/pdf/tonus.pdf. Acesso em: 17 fev. 2019.

UNITED NATIONS (UN) (2006). Commission on Human Rights. Promotion and protection of human rights: study on the right to the truth. Report E/CN.4/2006/91. Geneva: UN, 8 Feb.

\section{Nota}

O presente trabalho foi realizado com apoio do CNPq, Conselho Nacional de Desenvolvimento Científico e Tecnológico - Brasil. 